\title{
Lack of RsmA-Mediated Control Results in Constant Hypervirulence, Cell Elongation, and Hyperflagellation in Pectobacterium wasabiae
}

\author{
Viia Kõiv ${ }^{1 *}$, Liis Andresen ${ }^{1}$, Martin Broberg ${ }^{2}$, Jekaterina Frolova ${ }^{1}$, Panu Somervuo ${ }^{3}$, Petri Auvinen ${ }^{3}$, \\ Minna Pirhonen ${ }^{4}$, Tanel Tenson ${ }^{5}$, Andres Mäe ${ }^{1}$
}

1 University of Tartu, Institute of Molecular and CellBiology, Tartu, Estonia, 2 University of Helsinki, Department of Biosciences, Division of Genetics, Helsinki, Finland, 3 University of Helsinki, Institute of Biotechnology, DNA Sequencing and GenomicsLaboratory, Helsinki, Finland, 4 University of Helsinki, Department of AgriculturalSciences, Helsinki, Finland, $\mathbf{5}$ University of Tartu, Institute of Technology, Tartu, Estonia

\begin{abstract}
The posttranscriptional regulator RsmA controls the production of plant cell wall degrading enzymes (PCWDE) and cell motility in the Pectobacterium genus of plant pathogens. In this study the physiological role of gene regulation by RsmA is under investigation. Disruption of rsmA gene of the Pectobacterium wasabiae strain, SCC3193 resulted in 3-fold decrease in growth rate and increased virulence. The comparison of mRNA levels of the $r s m A^{-}$mutant and wild-type using a genomewide microarray showed, that genes responsible for successful infection, i.e. virulence factors, motility, butanediol fermentation, various secretion systems etc. were up-regulated in the $r s m A^{-}$strain. The $r s m A^{-}$strain exhibited a higher propensity to swarm and produce PCWDE compared to the wild-type strain. Virulence experiments in potato tubers demonstrated that in spite of its more efficient tissue maceration, the $r s m A^{-}$strain's ability to survive within the host is reduced and the infection site is taken over by resident bacteria. Taken together, in the absence of RsmA, cells revert to a constitutively infective phenotype characterized by expression of virulence factors and swarming. We hypothesize that lack of control over these costly energetic processes results in decreased growth rate and fitness. In addition, our findings suggest a relationship between swarming and virulence in plant pathogens.
\end{abstract}

Citation: Kõiv V, Andresen L, Broberg M, Frolova J, Somervuo P, et al. (2013) Lack of RsmA-Mediated Control Results in Constant Hypervirulence, Cell Elongation, and Hyperflagellation in Pectobacterium wasabiae. PLoS ONE 8(1): e54248. doi:10.1371/journal.pone.0054248

Editor: Mikael Skurnik, University of Helsinki, Finland

Received August 17, 2012; Accepted December 10, 2012; Published January 23, 2013

Copyright: ( 2013 Kõiv et al. This is an open-access article distributed under the terms of the Creative Commons Attribution License, which permits unrestricted use, distribution, and reproduction in any medium, provided the original author and source are credited.

Funding: This work was funded by grants SF0180088s08 and SF0180166s08 from the Estonian Ministry of Education and Research; by the EU through the European Regional Development Fund through the Estonian Centre of Excellence in Genomics and through the Center of Excellence in Chemical Biology; by Academy of Finland grants (Center of Excellence program 2006-2011 grants 213509, 129628, and grants 136470, 120821 and 128566); by University of Helsinki; by Biocentrum Helsinki; by Biocenter Finland; by Finnish Doctoral Program in Plant Science. The funders had no role in study design, data collection and analysis, decision to publish, or preparation of the manuscript.

Competing Interests: The authors have declared that no competing interests exist.

*E-mail: pontu55@hot.ee

\section{Introduction}

Members of the Pectobacterium genus are plant pathogens responsible for causing soft rot in numerous types of plants, including economically important carrot and potato crops. The main factors of pathogenicity involve bacterial motility and production of plant cell wall degrading enzymes (PCWDE). The latter include pectinases, cellulases, and proteases, and these are produced in large amounts following contact with a host plant [1]. To avoid a counterattack by a host, a pathogen attack must be fast and intense, thereby making it energetically expensive. Therefore, the expression of virulence factors is tightly controlled by environmental factors via a cellular regulatory network. In the genus Pectobacterium, there are three major, partly overlapping regulatory systems (Fig. 1). One involves the repressor protein, $\mathrm{KdgR}$, which suppresses the production of PCWDE without induction by host-related substances [2]. Second pathway involves quorum sensing that suppresses production of virulence factors before high population densities are reached within a plant host [3], [4]. In the third pathway, the flagellar master regulator, FlhDC, promotes the production of both flagella and PCWDE.
Thus, in Pectobacterium motility and production of virulence factors are coupled [5], [6].

The effect of quorum sensing on virulence factor production is mediated through the posttranscriptional regulator, RsmA [7]. RsmA binds to a target mRNA to down-regulate its translation and promote its degradation [8], [9], Andresen, L, unpublished data. FlhDC contributes to the control of virulence factor production through GacA $(\operatorname{ExpA})$, a positive regulator of the small regulatory RNA, RsmB [6]. RsmB binds RsmA, thereby releasing mRNA and neutralizing the negative effect of RsmA on mRNA translation. Hence, both quorum sensing and FlhDC contribute to RsmA-mediated posttranscriptional repression of virulence factors synthesis. In addition, although $\mathrm{KdgR}$ directly controls extracellular enzyme expression [10], Hyytiäinen et al. have demonstrated that $\mathrm{KdgR}$ controls also expression of the $r \mathrm{sm} B$ and $r s m A$ genes [11]. Consequently, the final regulatory step of virulence factor synthesis involves the posttranscriptional repressor RsmA (Fig. 1).

RsmA is a homolog of the RNA binding protein, CsrA, which was first described in E. coli as a regulator of glycogen biosynthesis [12]. In addition to controlling glycogen biosynthesis, CsrA and its 


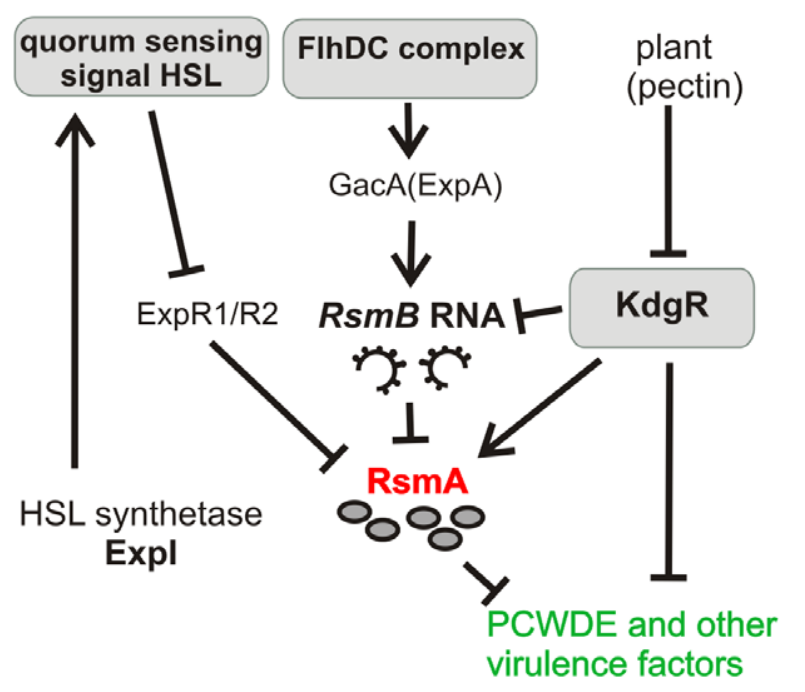

Figure 1. RsmA has a central role in regulating virulence factor synthesis in Pectobacteria. Arrowheads indicate positive regulatory effects and barred lines indicate negative effects. doi:10.1371/journal.pone.0054248.g001

homologs have widespread regulatory functions in bacteria, including roles in motility [13], central carbon metabolism [14] in E. coli, secondary metabolism, and numerous functions involving interactions between Pseudomonas fluorescens and plant hosts [15-17]. Correspondingly, entries in the protein families database, Pfam, indicate that homologues of CsrA/RsmA are present in a nearly half of bacterial species [18]. In some enterobacterial species, the $r s m A$ gene has been shown to be essential since its knock-out strain is not viable [19], [20]. However, depending on the growth conditions, inactivation of csrA in E. coli has been achieved [21]. Moreover, in Serratia marcescens and Pectobacterium carotovorum, rsmA-defective strains have also been reported [22], [23].

Here, we investigate the global regulatory role of RsmA in Pectobacterium wasabiae SCC3193 (Pw). Both microarray analysis and physiological characterizations of the $r s m A^{-}$mutant are reported. Our analysis reveals that $\mathrm{RsmA}$ is a key regulator involved in adaptation of $P w$ for infection/colonization of host plant.

\section{Materials and Methods}

\section{Bacterial strains and plasmids}

The Pectobacterium wasabiae wild-type strain, SCC3193 (previously identified as Pectobacterium carotovorum subsp. carotovorum), and its $r s m B$-defective mutant have been described previously [24-26]. To construct a Pw rsmA-deficient strain, the $r s m A$ sequence from the genomic DNA of SCC3193 was PCR amplified using primers, RAP17 (5'-TCTTTCAAGGAGGAAAGAATGG-3') and RAP18 (5'-CGCGAACACGAGACGCATTG-3'), and was subsequently cloned into the pUTmini-Tn5Km vector [27]. In the resulting construct, the $\operatorname{rsm} A$ gene was inactivated by cloning the cat gene $\left(\mathrm{Cm}^{\mathrm{R}}\right)$ into the BstEII restriction site. This vector construct was then used as a template to amplify $r s m A:: \mathrm{Cm}$ fragment (using primers RAP17 and RAP18), which was used to generate a $r s m A$ defective strain according to the method described by Datsenko and Wanner [28]. The resulting strain contained a chromosomal insertion of the chloramphenicol resistance gene 64 nucleotides downstream of the translational start codon of the rsmA coding sequence.
PCR-amplified rsmA (using primers RAP17 and RAP18) and $r s m B$ [using primers rsmB2 (5'-AATACATCTTATTACTTAAG$\left.3^{\prime}\right)$ and AE16AEPA (5'-AGCCAAGTGTGACTGACAGCATTTTT- $3^{\prime}$ )] genes were cloned into the Bluescript SK plasmid (Stratagene) and used to generate respective overexpression constructs.

The pLATSprtW construct was used to measure expression of $p r t W$. This construct contained the $p r t W$ gene promoter and twelve amino acids of coding sequence that were PCR amplified using primers, prtWpA (5'-TGCAGATACTGAGGTATCGT- $\left.3^{\prime}\right)$ and PROM8 (5'-AAGCTTACGCAGTGGGTCGTT-3'). The amplified fragment was cloned in frame with the gusA reporter gene in the low-copy vector, pMW119 (Eurogentec).

\section{Virulence assay in tobacco seedlings}

Virulence of the $P w$ wild-type and mutant strains was tested in 3-to-4-week-old tobacco seedlings (Nicotiana tabacum var. Samsun), grown in 24-well tissue culture plates in Murashige-Skoog medium. Seedlings were surface inoculated by pipetting bacterial solution $\left(10^{8}\right.$ bacterial cells) onto plants without wounding. The inoculated plants were incubated in a plant growth chamber with high humidity. The development of disease symptoms (i.e., tissue maceration) was monitored for $24-72 \mathrm{~h}$ after inoculation.

\section{Gene transcription level profiling}

Total RNA was isolated from wild-type and $r s m A$-defective strains grown on M9 minimal plates containing $10 \%$ potato tuber extract using Trizol reagent according to the manufacturer's protocol (Invitrogen). To eliminate any traces of genomic DNA prior to RNA amplification, an additional DNase I treatment was performed according to the supplier's protocol (Fermentas).

Extracted RNA from samples was checked for sufficient purity using NanoDrop and an Agilent bioanalyzer (containing a RNA Nano 6000 chip) prior to being treated with a MICROBexpress kit (Ambion) to remove $16 \mathrm{~S}$ and $23 \mathrm{~S}$ rRNAs. According to the manufacturer, this process significantly increases the sensitivity of downstream applications such as microarrays. Purified mRNA from each sample was checked for sufficiently low rRNA contamination using a bioanalyzer, and then was treated with a MessageAmp ${ }^{\text {TM }}$ II-Bacteria RNA Amplification kit (Applied Biosystems) according to the manufacturer's instructions. This kit was supplemented with 5-(3-aminoallyl)-UTP, ultimately producing antisense RNAs (aRNAs) which were subsequently labeled with fluorescent dyes (based on binding to the aminoallylUTP). The three different dyes used were: Alexa488 (Invitrogen), Cy3, and HyPer5 (Amersham). aRNA (5 $\mu$ g)for each biological replicate was dried in a vacuum centrifuge, then resuspended in $7 \mu \mathrm{l}$ sterile MQ water and $9 \mu \mathrm{l} \quad \mathrm{Na}_{2} \mathrm{CO}_{3}$ buffer ( $\mathrm{pH}$ 9.3). Fluorescent dye $(4 \mu \mathrm{l})$ was then added, and a different dye was incubated with each biological replicate. Samples were subsequently incubated at RT in darkness for $1 \mathrm{~h}$, then for an additional 15 min following the addition of $4 \mathrm{M}$ hydroxylamine $(4.5 \mu \mathrm{l} /$ sample). Samples were purified using a PureLink PCR purification kit (Invitrogen), then hybridized on an Agilent microarray for $17 \mathrm{~h}$ in a G2545 Agilent hybridization oven, according to the manufacturer's instructions (One-Color Microarray-Based Gene Expression Analysis Low Input Quick Amp Labeling, v6.5). The Agilent $8 * 15 \mathrm{k}$ custom microarray contains 60 mer probes covering a total 4571 ORFs.

The microarray slide was scanned using a Genepix 4110AL scanner (Axon Instruments) and analyzed with Genepix pro 6.1. Data were also analyzed using Bioconductor, a limma software package for the $\mathrm{R}$ programming language. Normalization was achieved using quantile normalization, empirical Bayesian vari- 
ance shrinkage was used for statistical analysis, and data were combined from all probes for each gene. A false discovery rate (fdr) value of 0.05 was used as the cut-off for significance in statistical analyses.

\section{Extracellular enzyme assays}

For the quantitative analysis of extracellular pectatelyases, polygalacturonase, and proteases, strains were grown in M9 minimal media [29] supplemented with appropriate trace elements [30] and a carbon source $(0.2 \%$ glucose or $0.2 \%$ polygalacturonic acid). Extracellular enzyme activities were measured in cell-free supernatant samples according to previously published protocols [31], [32]. To perform semi-quantitative agarose plate assays of extracellular protease and polygalacturonase production, cells were spotted on respective indicator plates described by Chatterjee and coworkers [23], with the exception that a milk-containing agar plate additionally contained $0.05 \%$ polygalacturonic acid as an inducer for proteases. Plates were incubated at $30^{\circ} \mathrm{C}$ and observed 24 and $72 \mathrm{~h}$ after incubation (for pectinolytic enzymes and proteases, respectively). Enzyme activity was evaluated according to the size of the halo around each colony, which is proportional to the amount of secreted enzyme.

\section{Analysis of prtW expression}

Strains containing the prtW::gusA translational fusion (pLATSprtW) were grown in M9 minimal medium supplemented with $10 \%$ celery extract. GusA activity was measured in the exponential and early stationary phases of growth using 4methylumbelliferyl $\beta$-d-glucuronide (DUCHEFA Biochemie) as a substrate, according to Andresen et al. [5].

\section{Identification of extracellular proteins}

Cell-free supernatants were collected from cultures grown in minimal glucose and PGA medium, and these samples were concentrated 20 times by acetone precipitation. Proteins were separated by SDS-PAGE (11\%) and protein bands were visualized using Comassie Blue R-250 staining. Proteins were cleaved with trypsin and Lys C proteases, analyzed by mass spectrometry (LTQ Orbitrap), and identified with searches against the SwissProt database using Mascot software.

\section{Motility tests}

The swimming phenotype of $P w$ strains were evaluated by stabbing fresh cultures with sterile toothpicks and then inserting the toothpicks into $0.25 \%$ soft agar plates containing M9 minimal medium with trace elements and $0.4 \%$ polygalacturonic acid as a carbon source.

Swarming motility was assayed by spotting each strain onto minimal plates containing $0.4 \%$ agar and $10 \%$ potato tuber extract.

Both swimming and swarming motility phenotypes for each strain were evaluated visually by observing the migration of cells away from the inoculation site.

\section{Flagella staining}

Macerated potato tuber tissues $(\sim 0.2 \mathrm{~g}$ each $)$ were gently soaked in $1 \mathrm{ml}$ distilled water, cut into small pieces without any agitation, and placed in tubes. Samples were left to stand for $\sim 15$ min until the pieces of potato precipitated. The upper bacterial suspension was then removed $(\sim 500 \mu \mathrm{l})$ to a new Eppendorf tube and centrifuged for $3 \mathrm{~min}$ at $100 \mathrm{~g}$. The upper aqueous phase was removed and the cells were gently resuspended in an appropriate volume of distilled water. This bacterial solution
$(10 \mu \mathrm{l})$ was immediately pipeted onto a microscope slide and left to dry very slowly under a cover before staining of flagella was performed according to West et al [33].

\section{Glycogen accumulation}

The glycogen content of each strain was evaluated on solid Kornberg medium $\left(1.1 \% \mathrm{~K}_{2} \mathrm{HPO}_{4}, 0.85 \% \mathrm{KH}_{2} \mathrm{PO}_{4}, 0.6 \%\right.$ yeast extract, $1 \%$ glucose) agar plates. Strains were grown on these plates for $24 \mathrm{~h}$ at $30^{\circ} \mathrm{C}$ then exposed to iodine vapor for $10 \mathrm{~min}$ to assess glycogen accumulation.

\section{Characterization of butanediol fermentation products}

Potato tubers were inoculated with $5 \times 10^{6}$ bacterial cells suspended in $10 \mathrm{mM} \mathrm{MgSO}$. After 24 and $48 \mathrm{~h}$ at $30^{\circ} \mathrm{C}$, tubers were cut in half and macerated tissue present was removed from the inoculation site into Eppendorf tubes. Following centrifugation at $15700 \mathrm{~g}$ for $10 \mathrm{~min}$, supernatants were analyzed using the Voges-Proskauer test [34]. A red color indicated the presence of acetoin, and its accumulation was quantified at OD530 $\mathrm{nm}$.

\section{Virulence assay in potato tubers}

Surface-sterilized potato tubers (cv. Ants) were stabbed with a sterile pipette tip and solutions of wild-type or $r s m A^{-}$cells $\left(5 \times 10^{6}\right)$ in $10 \mathrm{mM} \mathrm{MgSO}_{4}$ were transferred into the wound. Negative controls were inoculated with sterile $10 \mathrm{mM} \mathrm{MgSO}_{4}$. Tubers were kept at $30^{\circ} \mathrm{C}$ under plastic to maintain moist conditions. Virulence was estimated by weighing the rotted tissue present in tubers 20 and $40 \mathrm{~h}$ after inoculation.

To estimate the number of bacteria present in the infection sites, ca $2.5 \mathrm{~g}$ of tissue surrounding the infection site was resected, weighed, and homogenized in sterile $0.9 \% \mathrm{NaCl}$. Dilutions for CFU counting were plated on $\mathrm{LB}$ agar plates, except for $r s m A^{-}$ cells which were plated on LB plates containing $\mathrm{Cm}$. Colonies were counted after plates were incubated for 24 or $72 \mathrm{~h}$ at $30^{\circ} \mathrm{C}$ for wild-type and $r s m A^{-}$strains, respectively. To distinguish between $P w$ and other species of bacteria inhabiting the tubers, colonies were tested for the production of PCWDE on indicator plates.

\section{Results}

\section{Construction of the rsmA knockout}

To generate a knockout mutant of rsmA in the Pw, a $\mathrm{Cm}$ resistant marker was inserted into the $r s m A$ gene 64 nucleotides downstream of the translational start codon. The resulting $r s m A^{-}$ strain was observed to have a slower growth rate than the wildtype $P w$, independent of the medium used. To examine the physiological parameters of $r s m A^{-}$growth, liquid minimal medium containing a sole carbon source, $0.2 \%$ glucose or $0.2 \%$ polygalacturonic acid (PGA) was used. PGA mimics a plant component for induction of PCWDE. The $r s m A^{-}$was compared to both wild-type and $r s m B^{-}$strains. The generation times for wild-type, $r s m B^{-}$, and $r s m A^{-}$strains in $0.2 \%$ glucose were 73,75 , and $240 \mathrm{~min}$, respectively. In $0.2 \%$ PGA, the generation times were 85, 88, and $230 \mathrm{~min}$, respectively. Accordingly, the $r s m A^{-}$ strain grows 2.5-3 times more slowly than wild-type or $r s m B^{-}$ strains.

Next, the virulence of the $r s m A^{-}$mutant was compared with wild-type and $r s m B^{-}$strains in 3-to-4-week-old tobacco seedlings (Fig. S1). Three days post inoculation, there were no disease symptoms observed in plants infected with the $r s m B^{-}$mutant. In contrast, $63 \%$ of $r s m A^{-}$-infected plants, and $22 \%$ of plants infected with the wild-type strain, were completely macerated. Based on 
these results, the $r s m A^{-}$strain appears to have increased virulence despite exhibiting a reduced growth rate.

\section{RNA microarray analysis}

To elucidate the mechanism(s) mediating the increase in tissue maceration associated with the $r s m A^{-}$mutant, global transcript level analysis was performed for Pw. For these studies, a DNA microarray containing 4571 open reading frames (ORFs) of $P w$ was used. Total RNAs were extracted from wild-type $P w$ and the $r s m A^{-}$strain that were grown on $1.5 \%$ agar containing solid minimal medium supplemented with $10 \%$ potato extract to mimic in planta growth conditions. Based on the differences in growth, samples were collected from the rsmA $A^{-}$strain 40 and $48 \mathrm{~h}$ post inoculation, while wild-type samples were collected after $24 \mathrm{~h}$. RNA pools for these samples were then hybridized to microarrays and the gene transcript level profiles obtained were compared.

Although differences in the mRNA expression levels between wild-type and $r s m A^{-}$strains were not large, $39 \%$ of the ORFs analyzed (i.e., $1800 \mathrm{ORFs}$ ) showed statistically significant differences between the two strains $(\mathrm{p} \leq 0.05)$. In addition, the number of ORFs with differences between the $r s m A^{-}$strain and wild-type was considerably higher at the $40 \mathrm{~h}$ time point than at the $48 \mathrm{~h}$ time point (1631 vs. 565, respectively). The number of ORFs exhibiting differences at both time points was 396 . In all cases, approximately half of the differentially expressed ORFs were transcribed at higher levels in the $r s m A^{-}$strain than in the wild-type strain (available in NCBI GEO database, seires accession: GSE40333; ID: 200040333).

To analyze the universal role of rsmA in Pectobacteria, the results of the Pw microarray were compared with previously reported results from a microarray analyzing mRNA level profiles of wildtype $P$. atrosepticum $(\mathrm{Pa})$ versus an $\exp \Gamma$ strain [3]. The inactivation of $\exp I$ leads to increase in RsmA level (Fig. 1) [7]. Although the conditions in which the cells were grown prior to RNA extraction were different (plates containing potato extract for Pw vs. potato plant for $P a$ ), there were several genes with mRNA levels showing trends in opposite direction in the two experiments, as would be expected for the opposite rsmA expression levels (Fig. 2). In addition to known virulence factors, PCWDE and flagella, that were up regulated in $r s m A^{-}$strain and down regulated in exp $\Gamma$ strain, there were several groups of genes showing large effects: type VI secretion system, the phosphonate cluster, glycogen metabolism, citrate uptake and degradation, butanediol fermentation and TCA cycle, whereas the genes for cell division, peptidoglycan synthesis and lipopolysaccharide synthesis were down regulated in $r s m A^{-}$strain and up regulated in $\exp \Gamma$ strain (Fig. 2).

In subsequent experiments, the contribution of RsmA to infection/virulence-linked physiological traits and the general energetic state of the cell are further examined.

\section{Plant cell wall degrading enzymes (PCWDE)}

Levels of mRNA for PCWDE and genes coding for export systems for PCWDE, were found to be at higher levels in the rsmA defective strain than in the wild-type strain. To better understand these microarray data, the $r s m A^{-}$strain and the wild-type strain were grown in liquid minimal medium containing either $0.2 \%$ glucose or $0.2 \%$ PGA as the sole carbon source. The activity of three PCWDE was then assayed throughout their growth curves. These included polygalacturonase (Peh), pectatelyases (Pel), and protease (Prt) (Fig. 3). In glucose medium, the levels of Peh activity were 5-7 times higher in the $r s m A^{-}$strain than in the wild-type strain. Moreover, in $r s m A^{-}$mutants, levels of Peh activity were similar for glucose and PGA samples, while wild-type cells exhibited a clear induction of Peh activity by the plant component PGA. In contrast, levels of Peh activity in the $\operatorname{rsm} B$ knockout were not considerable.

Pel activity was also higher in the $r s m A^{-}$strain compared to the wild-type strain, and induction by PGA was minimal. For the $r_{s m B}{ }^{-}$strain, Pel activity was only detectable in cells grown with PGA (Fig. 3).

It was also observed that $\mathrm{Pel}$ and Peh production started earlier in the $r s m A^{-}$strain compared with the wild-type strain (data not shown). A lack of quorum sensing in the $r s m A^{-}$strain is a probable explanation for this phenomenon. Transcription of $r s m A$ in wildtype $P w$ is under the negative control of the quorum sensing signal, homoserine lactone (HSL) [7]. ExpR1/R2 proteins activate the transcription of $r s m A$ until HSL accumulates, and then HSL binds ExpR1/R2 to release the complex from the promoter region of rsmA (Fig. 1) [35]. Thus, in the late exponential phase of wild-type $P w$, the accumulated HSL removes activation of RsmA synthesis that causes induction of Peh and Pel. In the absence of RsmA this regulatory cascade is interrupted and the knockout strain is constantly in state similar to the wild-type strain in the late exponential phase.

Based on the microarray data collected, it was hypothesized that the protease activity of the $r s m A^{-}$strain would be high. However, although the protease activity of cells grown in glucose was slightly higher in the $r s m A^{-}$strain versus the wild-type strain, $r s m A^{-}$cells exhibited $\sim 5$-fold lower levels of protease activity in PGA liquid culture than wild-type cells. Moreover, no detectable protease activity was present in $r s m B^{-}$cells, indicating that the Rsm system controls protease production. To clarify this apparent discrepancy, we added $r s m A$ gene or $r s m B$ gene on plasmid to wild type cells. Consistent with microarray data, over-expression of RsmA suppresses the protease production while the small RNA RsmB enhances the protease production in wild-type cells (Figs. 3, 4).

To further verify the mRNA level profiling data obtained, the $p r t W$ regulatory region was fused to the GusA coding region to detect $p r t W$ expression in wild-type, $r s m A^{-}$, and $r s m B^{-}$strains. As shown in Figure S2, the expression of GusA was higher in the $r s m A^{-}$strain than in the wild-type strain, while in the $r s m B^{-}$strain it was lower than in the wild-type strain. These results are consistent with the microarray data, and suggest that expression of $\operatorname{prt} W$ in the $r s m A^{-}$strain was down-regulated at the level of protein stability, protein export, or enzymatic activity.

\section{Extracellular proteins}

Although high levels of extracellular Peh and Pel activity were detected in the $r s m A^{-}$strain, it was not clear whether higher levels of extracellular protein expression by the $r s m A^{-}$strain were limited to PCWDE, or whether a general increase in protein export was involved. To distinguish between these possibilities, culture supernatants of wild-type and $r s m A^{-}$strains were concentrated and then separated by SDS-PAGE (Fig. 3E). Using mass spectrometry, the most abundant proteins detected in the $r s m A^{-}$ growth medium were PehA, Pell, Pel2, Pel3, and CelV, along with traces of flagellin, FliC, and translation elongation factor, EF$\mathrm{Tu}$. These results indicate that the increased extracellular protein production associated with the $r s m A^{-}$strain is specific to PCWDE.

\section{Motility}

According to the array data, majority of the genes that encode flagella proteins are up-regulated in the $r s m A^{-}$strain, in accordance with previous studies of the Rsm system [36]. It has also been shown in several bacteria, including Pectobacteria, that RsmA/CsrA represses motility [20], [22], [36], [37]. The increased synthesis of flagella proteins and the energy consumption 


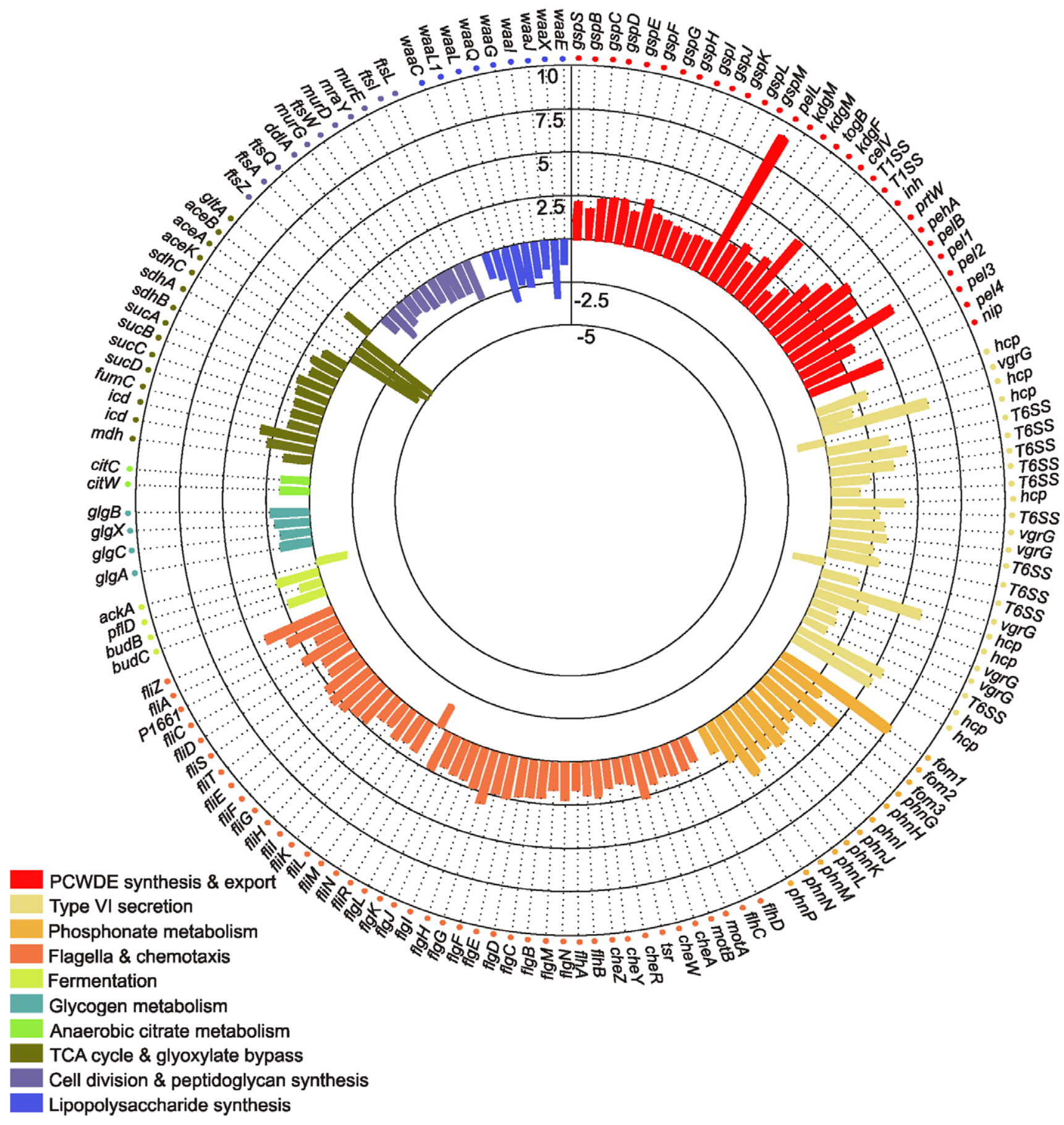

Figure 2. In Pectobacteria rsmA expression level affects transcriptome. A global mRNA profile of the $r s m A^{-}$of $P w$ was compared with its parental strain. The results were compared with a previous study of the exp/ ${ }^{-}$strain of $P a$ [3]. In the expl ${ }^{-}$strain the RsmA level is increased [7]. The genes included in the figure are those which passed two criteria: firstly, the expression level changes were in the opposite direction in response to rsmA inactivation as compared to $r s m A$ up-regulation (expl ${ }^{-}$strain); secondly, the genes have been associated with virulence. The scale bar(top of figure) represents the fold change in mRNA levels between the wild-type and the $r s m A^{-} P w$ strain, with positive values representing up-regulation and negative values representing down-regulation in the $r s m A^{-}$strain. doi:10.1371/journal.pone.0054248.g002

required for active flagella is a huge energetic commitment for a cell. To determine whether increased production of flagella in the rsmA $A^{-}$strain contributes to the slower growth rate observed, studies of motility, both swimming and swarming, were conducted for $r s m A^{-}, r s m B^{-}$, and wild-type strains (Fig. 5). While the $r s m B^{-}$ and wild-type strains exhibited similar rates of swimming, $r s m A^{-}$ cells were unable to spread in the $0.25 \%$ agar used for the assay. Moreover, this inability to swim was observed in PGA, glucose and glycerol media but not when 20 amino acids at final concentration of $100 \mu \mathrm{g} / \mathrm{ml}$ each were added to these media (data not shown). In addition, the swimming activity of the three strains was subsequently examined in liquid media using a phase contrast 
A

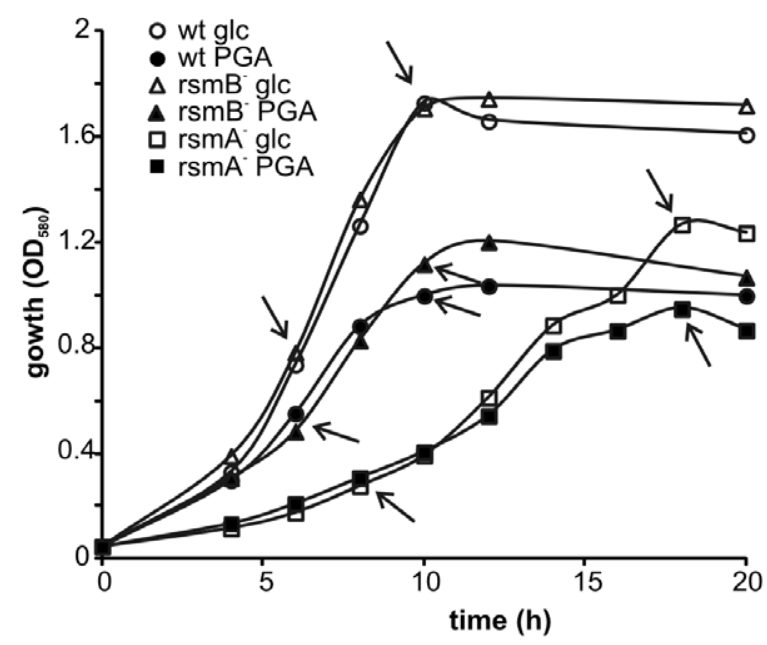

C

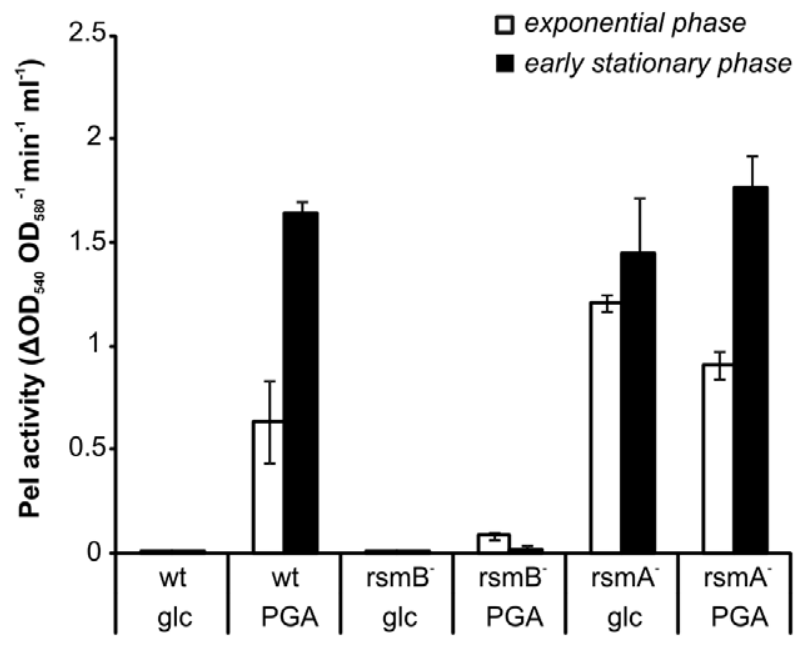

B

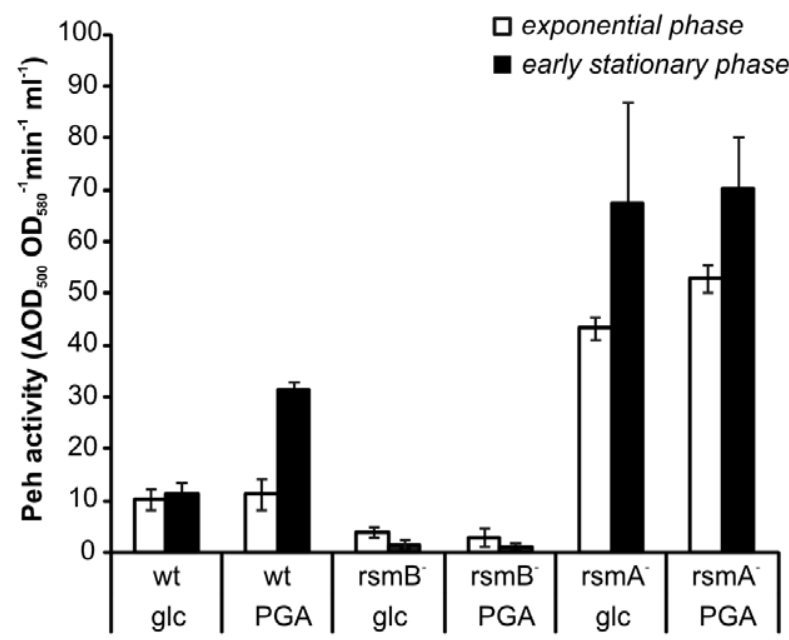

D

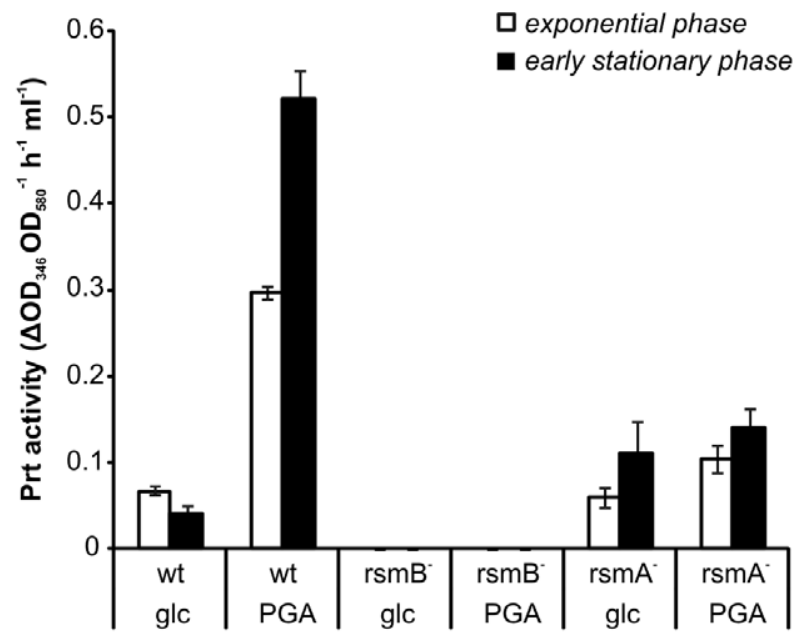

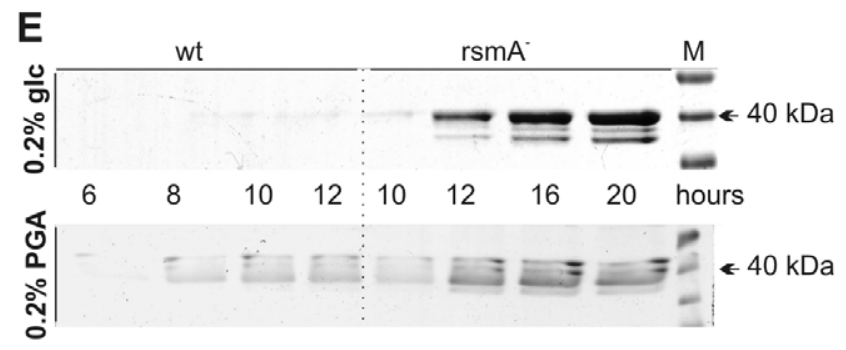

Figure 3. The rsmA mutant produces high levels of pectinolytic enzymes which constitute the majority of the proteins that are secreted. Wild-type (wt), $r s m A^{-}$, and $r s m B^{-}$cells were grown in minimal medium containing either $0.2 \%$ glucose (glc) or $0.2 \%$ polygalacturonic acid (PGA). Cell-free supernatants were then collected at various timepoints to evaluate protein content. A. The growth curves obtained for each strain and growth condition. The arrows indicate the timepoints used for collecting supernatant samples. B-D. Activity of polygalacturonase (Peh) (B), pectate lyases (Pel) (C), and proteases (Prt) (D) in supernatant samples collected from the exponential phase (white) and the early stationary phase (black) for each strain indicated. The average activity values for three independent experiments are represented. Error bars indicate the standard deviation values. E. Proteins in the wild-type and $r s m A^{-}$strain culture supernatants were concentrated20 times by acetone precipitation and separated by SDS PAGE. M indicates molecular weight marker.

doi:10.1371/journal.pone.0054248.g003 


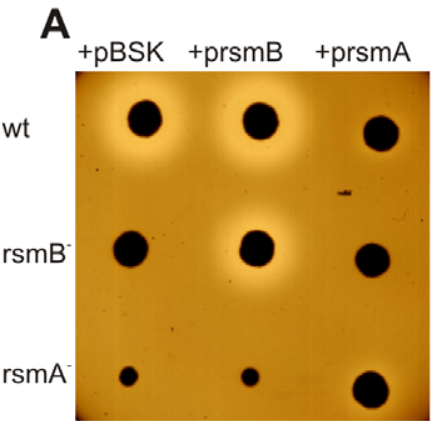

B

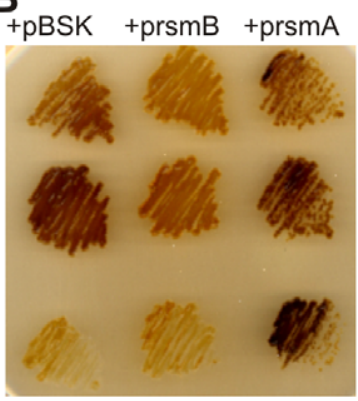

Figure 4. Plasmid expression of $r s m A$ or $r s m B$ can complement the corresponding knock-out mutants. A. The production of protease (Prt) was assayed using a specific, semi-quantitative indicator plate, where the halo around the inoculation site was proportional to the amount of enzyme produced. Exogenous expression of $r s m A$ and rsmB (prsmA and prsmB, respectively) was achieved, with pBSK being the vector control. B. To assess glycogen accumulation, cells were grown on Kornberg's medium then exposed to iodine vapors. Darker staining represents higher levels of glycogen. Assays were performed at least three times, and no significant variations were observed. doi:10.1371/journal.pone.0054248.g004

microscope. Cells were grown in $0.2 \%$ glucose or $0.2 \%$ PGA minimal medium and samples were collected at various points throughout their growth curves. In this assay, all three strains were observed to be motile. This suggests that the knock out strain has functional flagellae. The inability to swim is probably caused by a defect in the signaling that activated swimming i.e. chemotaxis.

Swarming motility generally requires an energy-rich, solid medium. However, the conditions specific for inducing swarming can vary for different bacteria [38]. In this study, swarming motility was assayed on $0.4 \%$ agar plates with different rich media containing celery extract or potato tuber extract to simulate plant induction. Swarming was only observed on plates containing $10 \%$ potato tuber extract. $R s m A^{-}$cells were observed to swarm rather quickly across the semi-solid surface, covering it with a hardly visible layer of cells (Fig. 5). In contrast, wild-type cells started to swarm on the third day of incubation (data not shown), while $r s m B^{-}$cells remained at the site of inoculation. The increased swarming activity observed for the $r s m A^{-}$strain is in accordance with the increased production of flagella detected in the microarray data.

Swarmer cells have been characterized as elongated and hyperflagellated, and secrete wetting agents to facilitate spreading over semi-solid surfaces [38-42]. Swarming bacteria increase the number of flagella per cell in a period of time referred to as the "swarming lag". As indicated above, the swarming lag for wildtype cells was 3 days, while $r s m A^{-}$cells did not exhibit a lag period. Similarly, PGWDE production was found to have a lag period in wild-type cells, yet not in the $r s m A^{-}$strain. Taken together, these data suggest that during the lag period in wild-type cells, both swarming and PCWDE production are repressed by RsmA, and this repression can be removed by HSL-mediated quorum sensing.

Next, silver-stained flagella were examined using a light microscope (Fig. 6). For these assays, cells were suspended in water prior to staining. When $r s m A^{-}$cells were collected from a potato extract-containing plate, they were observed to be rather sticky. It was found that the mordant tannin used for thickening flagella was stuck to an unknown substance on the cell surface, resulting in significant distortion of each cell's shape. By performing an additional washing step with water, the cells were able to be separated. In liquid media, $r s m A^{-}, r s m B^{-}$, and wild-type cells of all strains were observed to be rod-shaped and similarly flagellated (Fig. 6). This suggests that the decreased growth rate in liquid culture of the $r s m A^{-}$strain is not caused by increased production of flagella. However, when cells were grown for $24 \mathrm{~h}$ on plates containing potato extract, wild-type and $r s m B^{-}$cells maintained a rod-shape and were "normally" flagellated, while most of the $r s m A^{-}$cells were longer and hyper-flagellated in both $0.4 \%$ agar (i.e., the swarming plate) and $1.5 \%$ agar (i.e., medium from which samples were prepared for microarray analysis). Upon further incubation, the cell morphology of the rsm mutants remained unchanged. However, the wild-type cells became longer and more flagellated concurrent with the onset of swarming motility (data not shown).

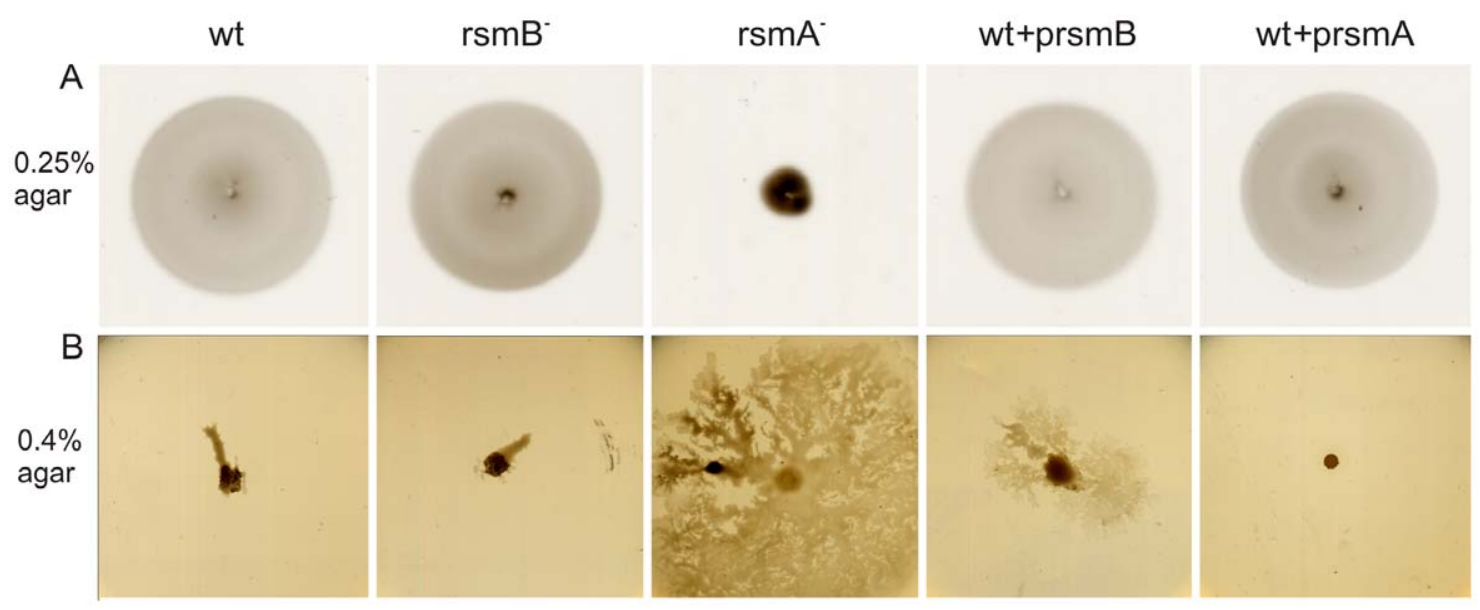

Figure 5. RsmA affects the swimming and swarming motility of $P w$. A. The swimming ability of wild-type, $r s m$ mutants ( $r s m A^{-}$and $\left.r s m B^{-}\right)$, and the respective overexpression strains ( $\mathrm{wt}+\mathrm{prsmA}$ and $\mathrm{wt}+\mathrm{prsmB}$ ) were evaluated based on the migration speed of these cells in $0.25 \%$ soft agar plates containing polygalacturonic acid. Cells were imaged $48 \mathrm{~h}$ after inoculation. B. The swarming ability of the wild-type, $r s m$ mutants $\left(r s m A^{-}\right.$and $\left.r s m B^{-}\right)$, and the respective overexpression strains (wt+prsmA and wt + prsmB) were evaluated. The ability of the cells to migrate on the surface of the medium, away from the site of inoculation was examined on $0.4 \%$ agar plates containing $10 \%$ potato extract. Plates were imaged $24 \mathrm{~h}$ after inoculation. Swarming of the wild-type strain was not observed until $72 \mathrm{~h}$ after inoculation (not shown). All images are representative of five different experiments performed, and no significant variability was observed between the experiments.

doi:10.1371/journal.pone.0054248.g005 


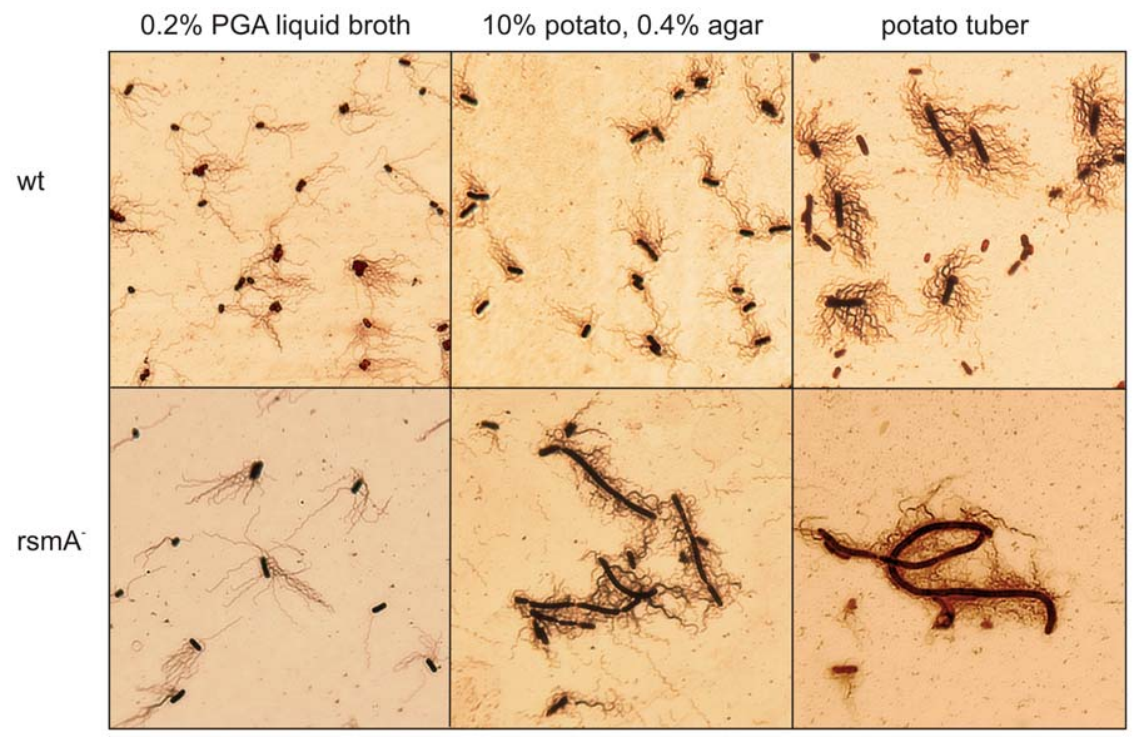

Figure 6. Pw cells change their shape and flagellation depending on their growth environment. Wild-type (wt) and $r s m A^{-}$strains grown in different media, as indicated, had their flagella stained according to West et al. [33]. Representative images of cells grown in the liquid medium ( $0.2 \%$ PGA liquid broth), swarming plate ( $0.4 \%$ agar containing $10 \%$ potato extract)and potato tuber are shown. The samples from potato tubers were collected $20 \mathrm{~h}$ after inoculation, all the other samples $24 \mathrm{~h}$ after inoculation. On the swarming plate the wild-type cells became long and hyperflagellated after $72 \mathrm{~h}$ of inoculation (not shown).

doi:10.1371/journal.pone.0054248.g006

\section{TCA cycle, glyoxylate shunt, and glycogen metabolism}

The reduced growth rate of $r s m A^{-}$mutants may be linked to a low energy state for these cells that is caused by increased

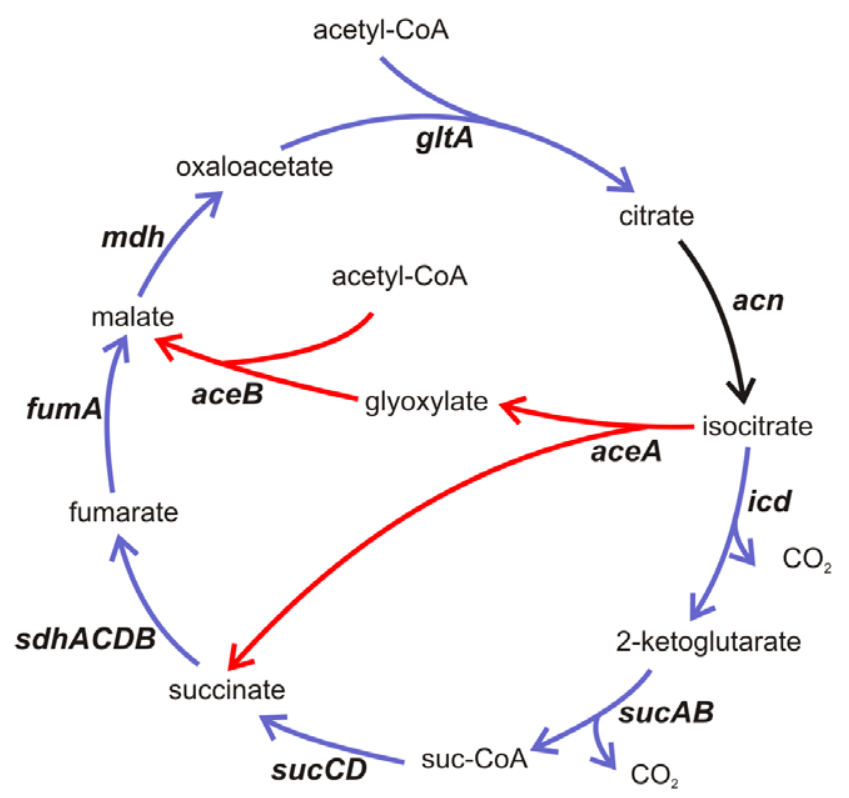

Figure 7. The role of RsmA in regulating the tricarboxylic acid (TCA) cycle and glyoxylate bypass. Blue arrows indicate reactions catalysed by the enzymes corresponding to genes up-regulated in the $r s m A^{-}$strain according to microarray data. Red arrows indicate reactions catalysed by the enzymes corresponding to genes downregulated in the $r s m A^{-}$strain. icd-isocitrate dehydrogenase; sucA-2ketoglutarate dehydrogenase; sucCD-succinyl CoA synthetase; sdhACDB-succinate dehydrogenase; fumA-fumarase; $m d h$-malate dehydrogenase; glt $A$-citrate synthase; acn-aconitase; aceA-isocitratelyase; aceB-malate synthase.

doi:10.1371/journal.pone.0054248.g007 production of virulence factors. The mRNA levels of genes involved in the glyoxylate shunt were found to be down-regulated, and genes for the TCA cycle were up-regulated, in the microarray data obtained (Figs. 2, 7).

The microarray analysis performed detected the up-regulation of genes for glycogen synthesis, including $g \lg A, g \lg C$, and $g \lg B$, as well as a gene for glycogen degradation, $g \lg X$, in the $r s m A^{-}$strain (Fig. 2). To confirm these results, glycogen accumulation on solid Kornberg medium was assayed with iodine vapor staining. As shown in Figure 4, the $r s m A^{-}$strain had slightly decreased glycogen levels. In E. coli, the RsmA homologue, CsrA is a protein originally described as a regulator of carbon metabolism [12]. In $\operatorname{csr} A^{-}$knock-out, glycogen synthesis is favored and excess glycogen accumulation impairs viability [21]. Thus, in contrast with the $E$. coli csr $A^{-}$mutant, the Pw rsmA $A^{-}$mutant consumes resources rather than saves them, and the increased consumption of glycogen may be linked to the energy deficiency associated with the $r s m A^{-}$ mutant.

\section{Fermentation}

Under the low oxygen conditions of internal plant tissues, plantassociated Enterobacteriaceae commonly ferment sugars through the 2,3-butanediol pathway. In the $r s m A^{-}$mutant, the genes responsible for 2,3-butanediol production (i.e., budA, budB, and budC), were found to be slightly up-regulated in the microarray data collected (Fig. 2). To confirm these results, levels of acetoin, a predecessor of 2,3-butanediol,were detected in macerated potato tuber tissue infected with wild type or $r s m A^{-}$mutant cells. As shown in Figure 8, levels of 2,3-butanediol fermentation were higher in the $r s m A^{-}$strain, which accounts for the higher $\mathrm{pH}$ of macerated potato tuber tissue collected from the $r s m A^{-}$strain compared to

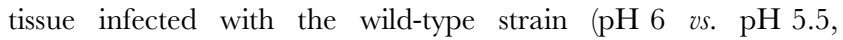
respectively).

The alkalization of growth media by 2,3-butanediol promotes the growth of bacteria that are unable to cope with acidic conditions in the plant. Therefore, the higher $\mathrm{pH}$ of potato tissue 


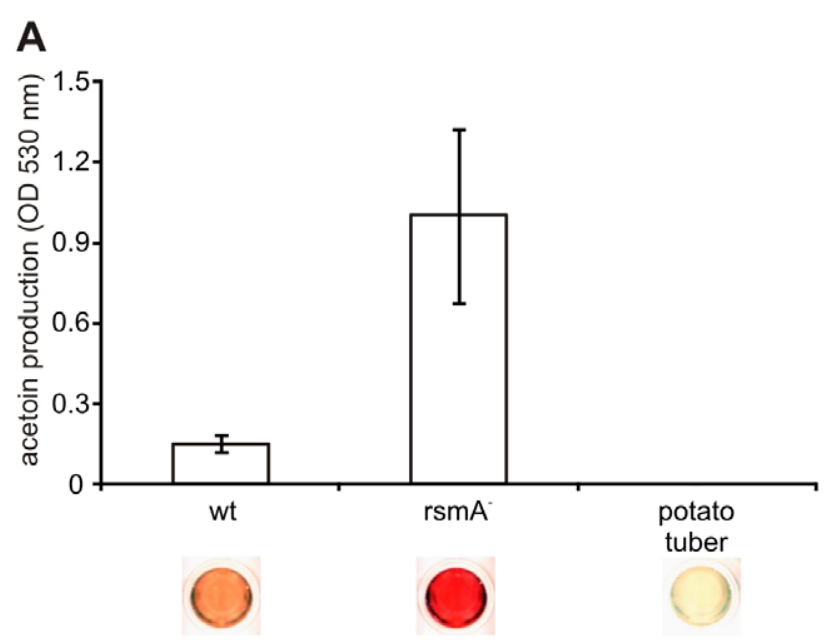

B

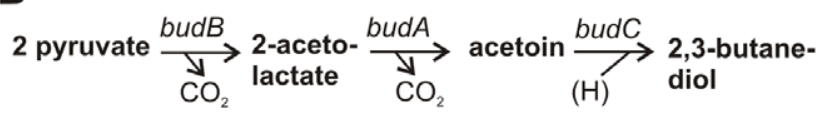

Figure 8. RsmA regulates butanediol fermentation in potato tubers. A. Potato tubers infected with wild-type (wt) or $r s m A^{-}$strains were assayed for activity of the butanediol fermentation pathway. Specifically, production of acetoin (an intermediate in the butanediol fermentation pathway) was detected spectrophotometrically (at $530 \mathrm{~nm}$ ) using the Voges-Proskauer method $24 \mathrm{~h}$ after inoculation [34]. The experiment was performed in triplicate and error bars indicate standard deviation values. The colorimetric reaction associated with each result is shown below the graph. B. The butanediol fermentation pathway in Pectobacteria. The reactions are catalysed by enzymes coded by budB (acetolactate synthase), budA ( $\alpha$-acetolactatedecarboxylase), and budC (acetoinreductase).

doi:10.1371/journal.pone.0054248.g008

may contribute to the increased virulence exhibited by the $r s m A^{-}$ strain (Figure S1).This is in agreement with the previous observations that inactivation of the bud genes of phytopathogenic bacteria from the genera, Dickeya and Pectobacterium reduce the virulence and fitness of these bacteria [43], [44].

\section{Citrate uptake}

Citrate is present at high concentrations in the plant apoplast [45], and is transported by a citrate-specific carrier/permeability system into the bacterial cell [46]. Correspondingly, the limiting step for the utilization of extracellular citrate by bacteria is the requirement for specific transporters. In the microarray data collected, increased mRNA levels of the gene cluster for citrate transport $(\mathrm{cit} W)$ and fermentation (citrate lyase citE, citC) were detected in the $r s m A^{-}$mutant (Fig. 2). To confirm these data, wildtype, $r s m B^{-}$, and $r s m A^{-}$cells were grown in minimal medium supplemented with $0.2 \%$ citrate as the sole carbon source. As shown in Figure 9, only rsm $A^{-}$cells were able to grow under these conditions. These data suggest that RsmA is involved in regulating the acquisition of different carbon sources during infection.

\section{Virulence in potato tubers}

Since potato tuber extracts were shown to induce swarming (Fig. 5), the relationship between swarming and potato tuber infections was investigated. For these studies, potato tubers were infected with wild-type or $r s m A^{-}$cells. At time points of 20 and $40 \mathrm{~h}$ post-infection, $r s m A^{-}$cells were found to produce up to three times more macerated tissue than wild-type cells (Fig. 10A).

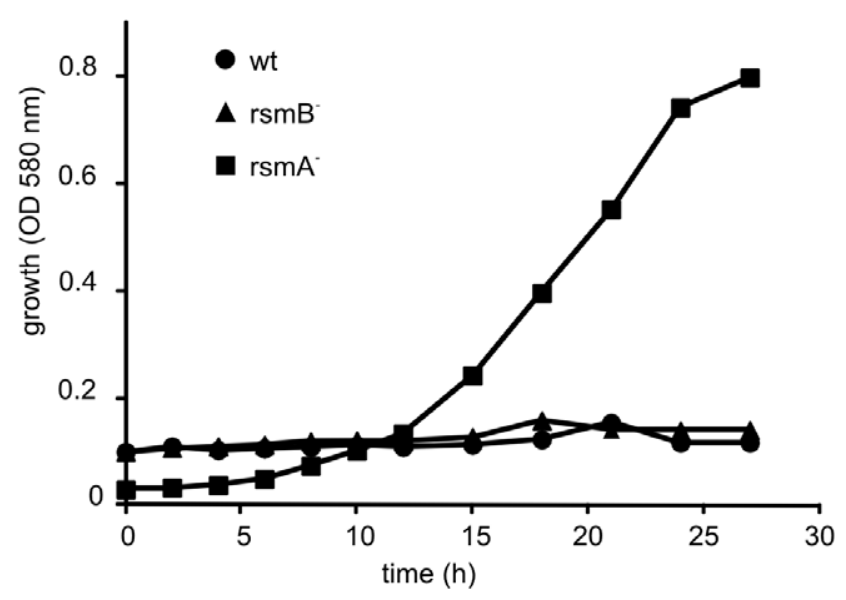

Figure 9. The RsmA mutant is able to grow aerobically on citric acid. Wild-type (wt), $r s m A^{-}$, and $r s m B^{-}$strains were tested for their ability to grow aerobically in minimal medium containing $0.2 \%$ citric acid as the sole carbon source. The absorbance of cultures at $580 \mathrm{~nm}$ was recorded up to $27 \mathrm{~h}$ post inoculation. Experiments were performed in triplicate.

doi:10.1371/journal.pone.0054248.g009

Since the generation time of the $r s m A^{-}$strain is 3-4 times slower than that of the wild-type strain, the ability of the $r s m A^{-}$strain to multiply in potato tubers was studied. For these studies, dilutions of macerated tissue generated from the incubation of potato tubers with either the wild-type or the $r s m A^{-}$strain were plated on LB. After $20 \mathrm{~h}$, in experiments with both strains the total bacterial numbers reached $\sim 10^{9}$ CFU per gram of macerated tissue (Fig. 10B). The plates with the wild-type strain contained uniform colonies with growth rate and PCWDE production identical to the original $P w$ strain. However, the LB plates inoculated with the dilutions of the $r s m A^{-}$macerated tissue contained colonies with variable colony morphologies and growth rates. This prompted us to plate the $r s m A^{-}$macerated tissue in parallel to the selective $\mathrm{LB}+\mathrm{Cm}$ plates. The number of cells growing in the presence of Cm was 2 magnitudes lower than the total colony count. Therefore, it appears that the $r s m A^{-}$strain represents only a minority of the bacteria present in macerated tissue. Moreover, the bacterial count in control tubers, inoculated with the buffer not generating macerated tissue was quite high, revealing the presence of resident microflora in the tubers (Fig. 10B). After $40 \mathrm{~h}$ of incubation the $r s m A^{-}$cells were almost completely disappeared and the infection site was taken over by the indigenous bacteria although the amount of macerated tissue was high. Taken together, these results demonstrate that although the $r s m A^{-}$ mutant is able to produce more virulence factors and causes more damage to plant tissue, its ability to cope with the resident micro flora or other conditions found in the potato tubers is reduced compared to the wild-type strain.

The effects of $r s m A^{-}$mutation on cell and flagella morphology were also examined in macerated tissues. At both time points, $20 \mathrm{~h}$ and $40 \mathrm{~h}$, wild-type cells were observed to be elongated and hyperflagellated. However, for the $r s m A^{-}$cells at the $20 \mathrm{~h}$ time point, cells were extremely long, filamentous, thin, and hyperflagellated, similar to the phenotype observed for $r s m A^{-}$cells on swarming plates. After $40 \mathrm{~h}$, it was difficult to detect $r s m A^{-}$cells due to the presence of numerous types of bacteria with various cell shapes.

In conclusion, the similarity of wild-type cells swarming on agar plates containing potato extract and cells isolated from potato tubers following infection suggests that the physiological state of 
A

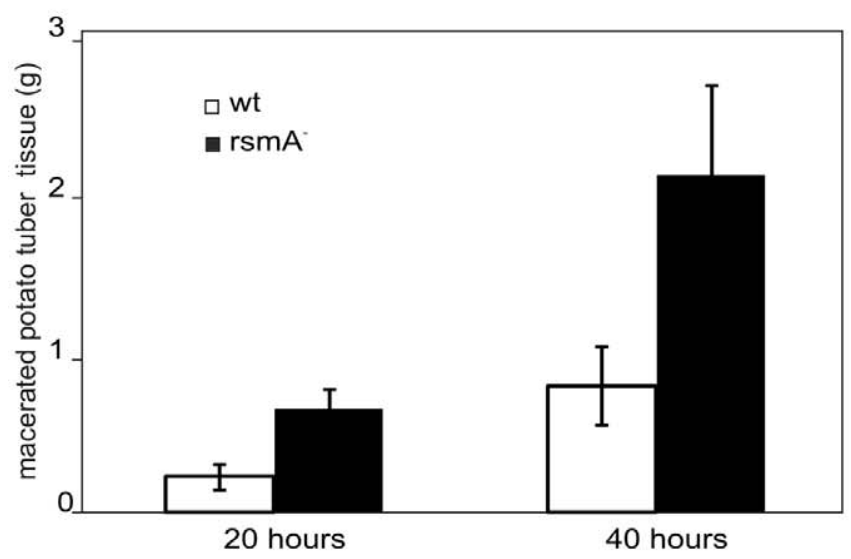

B

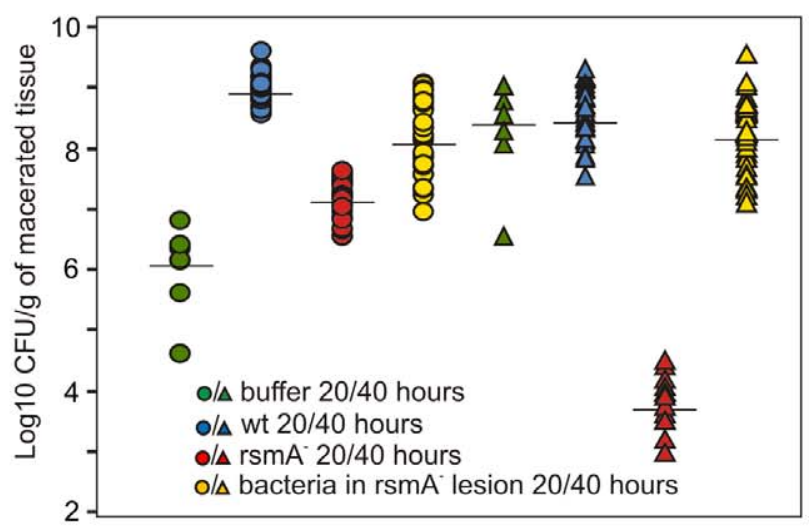

Figure 10. The virulence and survival of wild-type and $r s m A^{-}$strains over the course of potato tuber infections. Potato tubers $(\mathrm{n}=30)$ inoculated with $5 \times 10^{6} \mathrm{CFU}$ of wild-type (wt) or rsmA $A^{-}$cells were placed in plastic boxes and incubated at $30^{\circ} \mathrm{C}$. A. At $20 \mathrm{~h}$ and $40 \mathrm{~h}$ post inoculation, macerated tissue was removed from the inoculation site and weighed. Error bars indicate standard deviation values. B. The number of bacteria residing in the infection sites infected with wt, $r s m A^{-}$cells or buffer was determined by plating dilution series (green, blue and yellow). The number of $r s m A^{-}$bacteria present in infection sites was determined using $\mathrm{Cm}$-containing plates to avoid overgrowth by other bacteria inhabiting the infection sites (red). Circles and triangles represent data from the $20 \mathrm{~h}$ and $40 \mathrm{~h}$ time points assayed, respectively. Horizontal lines represent the median values.

doi:10.1371/journal.pone.0054248.g010

potato-infecting bacteria is similar to that of the swarming state. Moreover, the increase in swarming activity observed for the rsm $A^{-}$mutant suggests that RsmA is involved in the switch to a swarming phenotype.

\section{Discussion}

The microarray data collected in this study reveal global changes in physiology and metabolism occur in Pw with the loss of rsmA. Some of these changes involve the synthesis of PCWDE and other virulence factors, flagella synthesis and motility, the switch from glycogen production to glycogen consumption, increased citrate uptake, butanediol fermentation, and regulation of the TCA cycle to maximum energy production. These physiological processes are required for adaptation at the site of bacterial invasion in response to a host plant. In addition, when microarray data from deletion of $r s m A$ were compared with $r s m A$ overexpression in $\mathrm{Pa}$ (i.e., the $\exp \Gamma$ mutant) [3], several gene clusters strongly repressed by RsmA were identified. In particular, type VI secretion and phosphonate metabolism. The expression of these gene clusters has been shown to be promoted by plant extracts [47], although their functions in relation to virulence are unknown. We identified many additional genes that are oppositely regulated in response to $r s m A$ deletion and overexpression. As these genes have no obvious role in virulence, these were not analyzed in the current study and await for future investigations.

The slow growth phenotype of $r s m A^{-}$cells could be considered similar to those of strains expressing large quantities of nonfunctional, non-toxic proteins from multi-copy plasmids. In the case of $r s m A^{-}$cells, the "gratuitous" proteins are the highly produced PCWDEs, and these are not essential for bacterial growth. It has been shown that the accumulation of excessive proteins is accompanied by a progressive decrease in cell growth rates [48]. High growth rates require the continuous production of housekeeping proteins. Due to limited quantities of free RNA polymerase and ribosomes in the cell, the expression of excessive proteins thereby leads to a decrease in growth rate [49].
In the $r s m A$ knock out mRNA levels of genes involved in the glyoxylate shunt were found to be down-regulated, and genes for the TCA cycle were up-regulated (Figs. 2, 7). The glyoxylate bypass can provide anabolic intermediates; the TCA cycle is more efficient at providing energy. The glyoxylate shunt enzyme, isocitrate lyase (AceA) competes with the TCA cycle enzyme, isocitrate dehydrogenase (the product of $i c d$ ), for isocitrate. While isocitrate dehydrogenase has a much higher affinity for isocitrate, it is inactivated by phosphorylation when ATP concentrations are high and the cell needs precursors for biosynthesis [50]. Inhibition of isocitrate dehydrogenase then slows the TCA cycle and forces isocitrate through the bypass. When metabolic intermediates and AMP/ADP accumulate, isocitrate dehydrogenase is then dephosphorylated to function in the TCA cycle [50]. In the $r s m A^{-}$ mutant, increased mRNA levels of genes involved in TCA cycle might be a response to the limited energy resources of these cells. However, whether the up-regulation of proteins in the TCA cycle and the down-regulation of proteins that are part of the gyoxylate shunt is a consequence of the higher energy demand of the $r s m A^{-}$ strain, or is the direct result of gene regulation by RsmA, remains unsolved.

Both wild-type and $r s m A^{-} P w$ cells exhibited a swarming phenotype in potato tubers. In animal pathogens such as Proteus mirabilis, Salmonella typhimurium, Serratia marcescens, Pseudomonas aeruginosa, and Bacillus cereus, the swarming process is coupled with the invasion of new host cells and virulence factor synthesis [5154]. Furthermore, transcriptome studies of these bacteria have indicated that profound differences exist between swimmer and swarmer cells [51]. For example, morphological changes of swarmer cells include an increase in the number of flagella and cell elongation. Swarmer cell differentiation results in substantial alterations in metabolism and environmental survival strategies. Regarding the latter, these changes indicate that swarming represents a complex lifestyle adaptation. It has also been demonstrated in Salmonella and E. coli that a full TCA cycle is needed for swarming motility, a behavior that consumes a lot of energy [51],[55]. Similarly, up-regulation of the TCA cycle in the 
Pw rsm $A^{-}$strain would be predicted to be needed for up-regulation of virulence factor synthesis.

It is commonly believed that swarming cells suppress cell division, and that cell elongation is either a requirement for, or an indicator of, swarming motility. Regarding the filamentous cell shape of Pw swarming cells, there are three possible explanations. First, due to the energy required for cells to undergo swarming, cell division could be inhibited, thereby resulting in a filamentous cell shape. Secondly, stress induced by an antibiotic-like compound could be a factor. For example, swarming stimuli are poorly understood. However, they are hypothesized to be induced by environmental signals [56]. In $P w$, elongated cell shapes and hyperflagellation are promoted by a host. In this study, potato tubers or potato tuber extract were used to represent a host. If certain plant components act as an antibiotic, cell filamentation could be induced. Moreover, in potato tubers, the more susceptible $r s m A^{-}$strain was observed to undergo cell death. Thirdly, it is possible that the filamentous cell shape is induced by a potato tuber component which does not cause stress, but rather improves movement in the host.

The most probable reason for the low cell number observed for the $r s m A^{-}$strain in potato tubers is unregulated virulence factor synthesis. For example, once a pathogen penetrates a plant cellulose-based cell wall, the pathogen is exposed to plant extracellular surface receptors that recognize pathogen-associated molecular patterns (PAMP) such as bacterial flagellin and EF-Tu [57], [58]. This recognition triggers immunity, which usually halts an infection before a microbe can establish itself in the plant [59], [60]. Therefore, during infection, pathogens actively suppress a plant's PAMP-triggered defenses [61]. However, plants respond to cell wall damage by activating a variety of defenses [62]. In the $r s m A^{-}$strain, the Rsm system is compromised, thereby disrupting induction by quorum sensing and several other regulatory pathways. As a result, deregulated synthesis of PCWDE, flagellin, and other virulence factors occurs. Production of these proteins occurs in the $r s m A^{-}$mutant at higher level than in wild-type and may start before the bacteria have reached the critical cell concentration for attacking the plant. Flagellin, EF-Tu, acetoine, butanediol and a damaged cell wall can trigger plant defense responses [43], [44], [57], [58], which a single bacterial cell, although well equipped, cannot resist.

When studying bacteria numbers in infected potato tubers, it was found that despite surface-sterilization with hypochlorite acid prior to inoculation, the resident bacterial community of potato tubers can survive in considerable numbers. This may be due to fissures in the potato peel or bacteria present within the potato. In $r s m A^{-}$generated lesions, the number of bacteria present was particularly high, and included a variety of colony structures and sizes. This may be due to increased expression of PCWDE in the $r s m A^{-}$strain that could lead to the release of plant components at high levels. However, bacteria intrinsic to the potatoes used for

\section{References}

1. Pérombelon MCM (2002) Potato diseases caused by soft rot erwinias: an overview of pathogenesis. Plant Pathology 51: 1-12.

2. Liu Y, Jiang G, Cui Y, Mukherjee A, Ma WL, et al. (1999) kdgREcc negatively regulates genes for pectinases, cellulase, protease, HarpinEcc, and a global RNA regulator in Erwinia carotovora subsp. carotovora. J Bacteriol 181: 2411-2421.

3. Liu H, Coulthurst SJ, Pritchard L, Hedley PE, Ravensdale M, et al. (2008) Quorum sensing coordinates brute force and stealth modes of infection in the plant pathogen Pectobacterium atrosepticum. PLoS pathogens 4(6):e1000093. Available: http://www. pubmedcentral.nih.gov/articlerender.fcgi? artid $=2413422 \&$ tool $=$ pmcentrez \&rendertype $=$ abstract. Accessed 2012 Mar 9.

4. Põllumaa L, Alamäe T, Mäe A (2012) Quorum Sensing and Expression of Virulence in Pectobacteria. Sensors 12: 3327-3349. inoculation were also present for the wild-type experiments, indicating that the wild-type $P w$ strain was able to efficiently outcompete these organisms. We hypothesize that the maceration of potato tubers is achieved by a diverse population of bacteria. For example, $P w$ cannot degrade starch, which is the main carbohydrate present in potato tubers. Degradation of the plant cell wall by PCWDE of $P w$ could expose the starch present to other bacteria.

In conclusion, plant invasion is a hazardous and energy consuming process for bacteria, and accordingly, has to be tightly regulated. Therefore, the unregulated production of virulence factors at high levels in the $r s m A^{-}$strain is energetically costly, and can reduce the ability of $P w$ to invade a plant and compete with the natural bacterial community of the host. Moreover, in Pw, an attack of a plant and the induction of virulence factors are accompanied by a swarming phenotype.

\section{Supporting Information}

Figure S1 The Rsm system affects the ability of $P w$ to infect tobacco seedlings. Surface inoculations were performed on 3-to-4week-old seedlings, with $10^{8}$ wild-type, $r s m A$-, or $r s m B$-defective bacteria applied per seedling. A total of 24 seedlings were inoculated for each strain. White and black bars indicate the percentage of tobacco seedlings macerated 24 or $72 \mathrm{~h}$ postinoculation, respectively.

(TIF)

Figure S2 Expression of a $p r t W$ reporter gene fusion is dependent on the Rsm system. A prtW::gusA fusion was used to evaluate the effect of either $r s m B$ or $r s m A$ inactivation on protease (PrtW) expression. Cells were grown in minimal medium supplemented with $10 \%$ celery extract, and $\beta$-glucuronidase (GusA) activity was assayed in the exponential phase (white) and the early stationary phase (black) for each strain (i.e., 6 and $10 \mathrm{~h}$ post inoculation for the wild-type and $r s m B^{-}$strains; and 10 and $18 \mathrm{~h}$ post inoculation for the $r s m A^{-}$strain). The experiment was performed in triplicate and error bars indicate standard deviation values.

(TIF)

\section{Acknowledgments}

We thank Lauri Peil for assistance with the mass spectrometric analysis of proteins and Eeva Heinaru for advice on microbiological methods.

\section{Author Contributions}

Conceived and designed the experiments: VK LA. Performed the experiments: VK LA MB JF. Analyzed the data: VK LA MB. Contributed reagents/materials/analysis tools: PS PA MP TT AM. Wrote the paper: VK LA MP TT AM.

5. Andresen L, Sala E, Kõiv V, Mäe A (2010) A role for the Rcs phosphorelay in regulating expression of plant cell wall degrading enzymes in Pectobacterium carotovorum subsp. carotovorum. Microbiology 156: 1323-1334.

6. Cui Y, Chatterjee A, Yang H, Chatterjee AK (2008) Regulatory network controlling extracellular proteins in Enwinia carotovora subsp. carotovora: FlhDC, the master regulator of flagellar genes, activates $r s \mathrm{~m} B$ regulatory RNA production by affecting gacA and hexA (IrhA) expression. J Bacteriol 190: 4610-4623.

7. Kõiv V, Mäe A (2001) Quorum sensing controls the synthesis of virulence factors by modulating rsmA gene expression in Erwinia carotovora subsp. carotovora. Mol Genet Genomics 265: 287-292

8. Liu Y, Cui Y, Mukherjee A, Chatterjee AK (1998) Characterization of a novel RNA regulator of Erwinia carotovora ssp. carotovora that controls production of extracellular enzymes and secondary metabolites. Mol Microbiol 29: 219-234. 
9. Ma W, Cui Y, Liu Y, Dumenyo CK, Mukherjee A, et al. (2001) Molecular characterization of global regulatory RNA species that control pathogenicity factors in Erwinia amylovora and Erwinia herbicola pv. gypsophilae. J Bacteriol 183: $1870-1880$.

10. Hugouvieux-Cotte-Pattat N, Condemine G, Nasser W, Reverchon S (1996) Regulation of pectinolysis in Enwinia chrysanthemi. Ann Rev Microbiol 50: 213257.

11. Hyytiäinen H, Montesano M, Palva ET (2001) Global regulators ExpA (GacA) and KdgR modulate extracellular enzyme gene expression through the RsmArsmB system in Erwinia carotovora subsp. carotovora. Mol Plant-Microbe Int 14: 931938.

12. Romeo T, Gong M, Liu MY, Brun-Zinkernagel AM (1993) Identification and molecular characterization of csrA, a pleiotropic gene from Escherichia coli that affects glycogen biosynthesis, gluconeogenesis, cell size, and surface properties. J Bacteriol 175: 4744-4755

13. Wei BL, Brun-Zinkernagel AM, Simecka JW, Prüss BM, Babitzke P, et al. (2001) Positive regulation of motility and $f h D C$ expression by the RNA-binding protein CsrA of Escherichia coli. Mol Microbiol 40: 245-256.

14. Baker CS, Morozov I, Suzuki K, Romeo T, Babitzke P (2002) CsrA regulates glycogen biosynthesis by preventing translation of $g l g C$ in Escherichia coli. Mol Microbiol 44: 1599-1610.

15. Chao N-X, Wei K, Chen Q, Meng Q-L, Tang D-J, et al. (2008) The rsmA-like gene $r s m A_{\left(X_{c c}\right)}$ of Xanthomonas campestris pv. campestris is involved in the control of various cellular processes, including pathogenesis. Mol Plant-Microbe Interact 21: $411-423$.

16. Heeb S, Haas D (2001) Regulatory roles of the GacS/GacA two-component system in plant-associated and other gram-negative bacteria. Mol Plant-Microbe Interact 14: 1351-1363.

17. Heeb S, Valverde C, Gigot-Bonnefoy C, Haas D (2005) Role of the stress sigma factor RpoS in GacA/RsmA-controlled secondary metabolism and resistance to oxidative stress in Pseudomonas fluorescens CHA0. FEMS Microbiol Lett 243: 251258.

18. Punta M, Coggill PC, Eberhardt RY, Mistry J, Tate J, et al. (2012) The Pfam protein families database. Nucleic Acids Res 40: D290-301.

19. Altier C, Suyemoto M, Lawhon SD (2000) Regulation of Salmonella enterica serovar typhimurium invasion genes by csrA. Infect Immun 68: 6790-6797.

20. Liaw S-J, Lai H-C, Ho S-W, Luh K-T, Wang W-B (2003) Role of RsmA in the regulation of swarming motility and virulence factor expression in Proteus mirabilis. J Med Microbiol 52: 19-28.

21. Timmermans J, Van Melderen L (2009) Conditional essentiality of the $c s r A$ gene in Escherichia coli. J Bacteriol 191: 1722-1724.

22. Ang S, Horng YT, Shu JC, Soo PC, Liu JH, et al. (2001) The role of RsmA in the regulation of swarming motility in Serratia marcescens. J Biomed Sci 8: 160169.

23. Chatterjee A, Cui Y, Liu Y, Dumenyo CK, Chatterjee AK (1995) Inactivation of rsmA leads to overproduction of extracellular pectinases, cellulases, and proteases in Erwinia carotovora subsp. carotovora in the absence of the starvation/cell densitysensing signal, N-(3-oxohexanoyl)-L-homoserine lactone. Appl Environ Microbiol 61: 1959-1967.

24. Nykyri J, Niemi O, Koskinen P, Nokso-Koivisto J, Pasanen M, et al. (2012) Revised Phylogeny and Novel Horizontally Acquired Virulence Determinants of the Model Soft Rot Phytopathogen Pectobacterium wasabiae SCC3193. PLoS Pathog 8(11):e1003013. doi: 10.1371/journal.ppat.1003013.

25. Kõiv V, Andresen L, Mäe A (2010) AepA of Pectobacterium is not involved in the regulation of extracellular plant cell wall degrading enzymes production. Mol Genet Genomics 283: 541-549.

26. Pirhonen M, Heino P, Helander I, Harju P, Palva ET (1988) Bacteriophage T4 resistant mutants of the plant pathogen Erwinia carotovora. Microb Pathog 4: 359367.

27. Herrero M, de Lorenzo V, Timmis KN (1990) Transposon vectors containing non-antibiotic resistance selection markers for cloning and stable chromosomal insertion of foreign genes in gram-negative bacteria. J Bacteriol 172: 6557-6567.

28. Datsenko KA, Wanner BL (2000) One-step inactivation of chromosomal genes in Escherichia coli K-12 using PCR products. Proc Natl Acad Sci U S A 97: 6640 6645.

29. Sambrook J, Russell D (2001) Molecular Cloning: A Laboratory Manual. 3rd ed. Cold Spring Harbor Laboratory Press. p.

30. Bauchop T, Elsden SR (1960) The growth of micro-organisms in relation to their energy supply. J Gen Microbiol 23: 457-469.

31. Karlsson MB, Pirhonen M, Saarilahti HT, Palva ET (1991) Molecular cloning of ompRS, a regulatory locus controlling production of outer membrane proteins in Enwinia carotovora subsp. carotovora. Mol Gen genet 226: 353-360.

32. Marits R, Tshuikina M, Pirhonen M, Laasik E, Mäe A (2002) gusA fusions in Enwinia carotovora subsp. carotovora. Microbiology 148: 835-842.

33. West M, Burdash NM, Freimuth F (1977) Simplified silver-plating stain for flagella. J Clinic Microbiol 6: 414-419.

34. MacFaddin JF (1980) Biochemical tests for identification of medical bacteria. 2nd ed. Philadelphia, PA.: Lippincott Williams \& Wilkins.

35. Sjöblom S, Brader G, Koch G, Palva ET (2006) Cooperation of two distinct ExpR regulators controls quorum sensing specificity and virulence in the plant pathogen Enwinia carotovora. Mol Microbiol 60: 1474-1489.
36. Mukherjee A, Cui Y, Liu Y, Dumenyo CK, Chatterjee AK (1996) Global regulation in Erwinia species by Enwinia carotovora rsmA, a homologue of Escherichia coli csrA: repression of secondary metabolites, pathogenicity and hypersensitive reaction. Microbiology 142: 427-434.

37. Chatterjee A, Cui Y, Chakrabarty P, Chatterjee AK (2010) Regulation of motility in Erwinia carotovora subsp. carotovora: quorum-sensing signal controls FlhDC, the global regulator of flagellar and exoprotein genes, by modulating the production of RsmA, an RNA-binding protein. Mol Plant-Microbe Interact 23: 1316-1323.

38. Kearns DB (2010) A field guide to bacterial swarming motility. Nat Rev Microbiol 8: 634-644

39. Chen BG, Turner L, Berg HC (2007) The wetting agent required for swarming in Salmonella enterica serovar typhimurium is not a surfactant. J Bacteriol 189: 87508753.

40. Gygi D, Rahman MM, Lai HC, Carlson R, Guard-Petter J, et al. (1995) A cellsurface polysaccharide that facilitates rapid population migration by differentiated swarm cells of Proteus mirabilis. Mol Microbiol 17: 1167-1175.

41. Lindum PW, Anthoni U, Christophersen C, Eberl L, Molin S, et al. (1998) NAcyl-L-homoserine lactone autoinducers control production of an extracellular lipopeptide biosurfactant required for swarming motility of Serratia liquefaciens MG1. J Bacteriol 180: 6384-6388.

42. Neu TR (1996) Significance of bacterial surface-active compounds in interaction of bacteria with interfaces. Microbiol Rev 60: 151-166.

43. Effantin G, Rivasseau C, Gromova M, Bligny R, Hugouvieux-Cotte-Pattat N (2011) Massive production of butanediol during plant infection by phytopathogenic bacteria of the genera Dickeya and Pectobacterium. Mol Microbiol 82: 988997.

44. Marquez-Villavicencio M del P, Weber B, Witherell RA, Willis DK, Charkowski AO (2011) The 3-hydroxy-2-butanone pathway is required for Pectobacterium carotovorum pathogenesis. PloS one 6: e22974. Available: http://www. pubmedcentral.nih.gov/articlerender.fcgi? artid $=3158072 \&$ tool $=$ pmcentrez \&rendertype $=$ abstract. Accessed 2012 May 25.

45. Kania A, Langlade N, Martinoia E, Neumann G (2003) Phosphorus deficiencyinduced modifications in citrate catabolism and in cytosolic $\mathrm{pH}$ as related to citrate exudation in cluster roots of white lupin. Plant Soil 248: 117-127.

46. Urbany C, Neuhaus HE (2008) Citrate uptake into Pectobacterium atrosepticum is critical for bacterial virulence. Mol Plant-Microbe Interact 21: 547-554.

47. Mattinen L, Somervuo P, Nykyri J, Nissinen R, Kouvonen P, et al. (2008) Microarray profiling of host-extract-induced genes and characterization of the type VI secretion cluster in the potato pathogen Pectobacterium atrosepticum. Microbiology 154: 2387-2396.

48. Kurland CG, Dong H (1996) Bacterial growth inhibition by overproduction of protein. Mol Microbiol 21: 1-4.

49. Stoebel DM, Dean AM, Dykhuizen DE (2008) The cost of expression of Escherichia coli lac operon proteins is in the process, not in the products. Genetics 178: 1653-1660.

50. Cronan JEJ, Laporte D (2006) Tricarboxylic acid cycle and glyoxylate bypass. In: Neidhardt FC, Curtiss III R, Ingraham JL, Lin ECG, Low KB, et al., editors. In Escherichia coli and Salmonella: Cellular and Molecular Biology. Washington, D.C.: ASM PRESS. pp. 206-216.

51. Kim W, Surette MG (2004) Metabolic differentiation in actively swarming Salmonella. Mol Microbiol 54: 702-714.

52. Overhage J, Bains M, Brazas MD, Hancock REW (2008) Swarming of Pseudomonas aeruginosa is a complex adaptation leading to increased production of virulence factors and antibiotic resistance. J Bacteriol 190: 2671-2679.

53. Pearson MM, Rasko DA, Smith SN, Mobley HLT (2010) Transcriptome of swarming Proteus mirabilis. Infect Immun 78: 2834-2845.

54. Wang Q Frye JG, McClelland M, Harshey RM (2004) Gene expression patterns during swarming in Salmonella typhimurium: genes specific to surface growth and putative new motility and pathogenicity genes. Mol Microbiol 52: $169-187$.

55. Inoue T, Shingaki R, Hirose S, Waki K, Mori H, et al. (2007) Genome-wide screening of genes required for swarming motility in Escherichia coli K-12. J Bacteriol 189: 950-957.

56. Patrick JE, Kearns DB (2012) Swarming motility and the control of master regulators of flagellar biosynthesis. Mol Microbiol 83: 14-23.

57. Felix G, Duran JD, Volko S, Boller T (1999) Plants have a sensitive perception system for the most conserved domain of bacterial flagellin. Plant J Cell Mol Biol 18: 265-276.

58. Kunze G, Zipfel C, Robatzek S, Niehaus K, Boller T, et al. (2004) The N terminus of bacterial elongation factor Tu elicits innate immunity in Arabidopsis plants. The Plant Cell 16: 3496-3507.

59. Ausubel FM (2005) Are innate immune signaling pathways in plants and animals conserved? Nat Immun 6: 973-979.

60. Chisholm ST, Coaker G, Day B, Staskawicz BJ (2006) Host-microbe interactions: shaping the evolution of the plant immune response. Cell 124: 803-814.

61. Nürnberger T, Brunner F, Kemmerling B, Piater L (2004) Innate immunity in plants and animals: striking similarities and obvious differences. Immun Rev 198: 249-266.

62. Hématy K, Cherk C, Somerville S (2009) Host-pathogen warfare at the plant cell wall. Curr Opin Plant Biol 12: 406-413. 